\title{
NIF Capsule Design Update
}

T. R. Dittrich, S. W. Haan, S. Pollaine,

A. K. Burnham, G. L. Strobel

This paper was prepared for submittal to the Eleventh Target Fabrication Specialists' Meeting

Orcas Island, WA

September 8-12, 1996

October 8, 1996

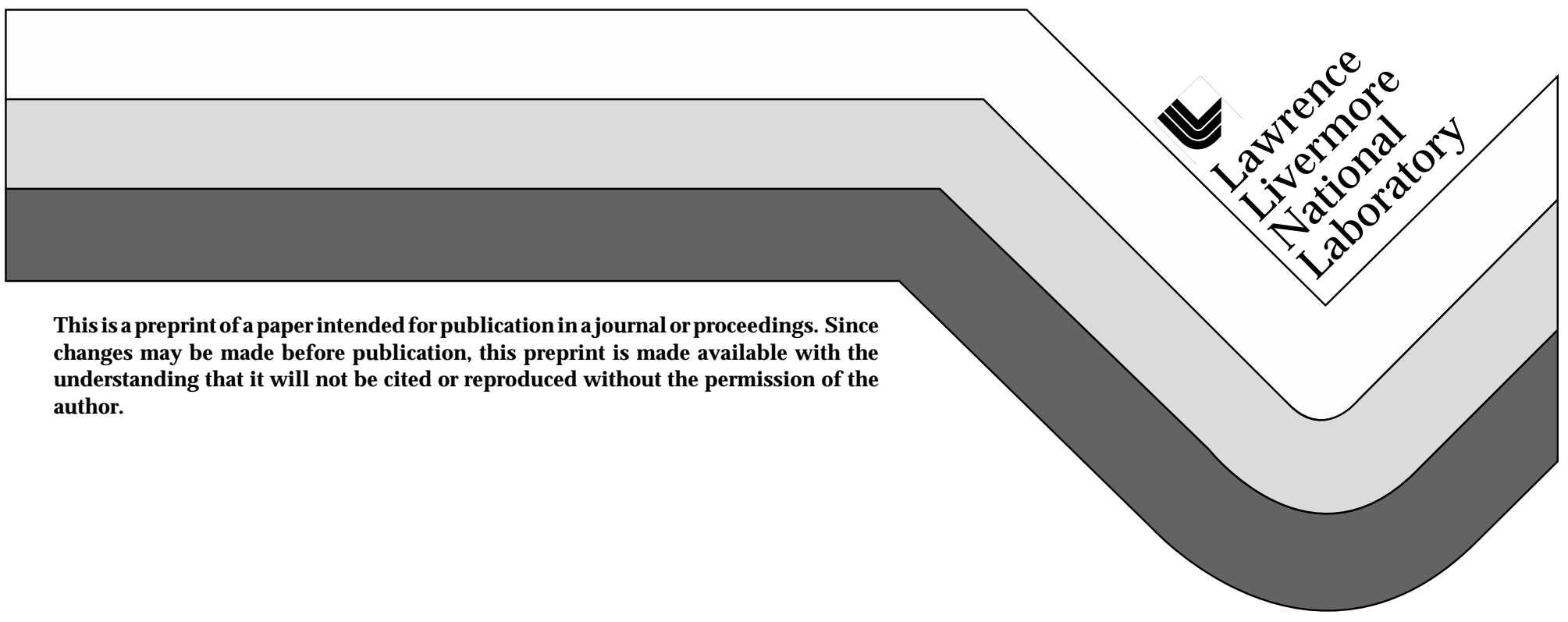




\section{DISCLAIMER}

This document was prepared as an account of work sponsored by an agency of the United States Government. Neither the United States Government nor the University of California nor any of their employees, makes any warranty, express or implied, or assumes any legal liability or responsibility for the accuracy, completeness, or usefulness of any information, apparatus, product, or process disclosed, or represents that its use would not infringe privately owned rights. Reference herein to any specific commercial product, process, or service by trade name, trademark, manufacturer, or otherwise, does not necessarily constitute or imply its endorsement, recommendation, or favoring by the United States Government or the University of California. The views and opinions of authors expressed herein do not necessarily state or reflect those of the United States Government or the University of California, and shall not be used for advertising or product endorsement purposes. 


\title{
NIF Capsule Design Update
}

\author{
T. R. Dittrich, S. W. Haan, S. Pollaine, A. K. Burnham, G. L. Strobel \\ Lawrence Livermore National Laboratory, Livermore, California 94551
}

\begin{abstract}
We describe several ignition capsule designs, for use in the National Ignition Facility. We will compare these designs for ablator efficiency, ignition margin, implosion and stability performance. This study includes capsule designs driven by $\mathrm{x}$-ray drive profiles with both $300 \mathrm{eV}$ and $250 \mathrm{eV}$ peak temperatures. All of the $300 \mathrm{eV}$ designs are tuned to implode the DT fuel in a nearly identical manner. Capsule designs consist of an ablator material (CH with $\mathrm{Br}$ dopant; $\mathrm{Be}$ with $\mathrm{Cu}$ dopant; and $\mathrm{B}_{4} \mathrm{C}$ ) encasing a layer of solid DT. The dopants alter material opacities sufficiently to 1) shield the DT fuel from preheat effects; and 2) develop an ablation front density profile favorable to implosion stability. $\mathrm{B}_{4} \mathrm{C}$ has sufficient opacity at $300 \mathrm{eV}$ that a dopant is not necessary. Issues relating to material properties and fabrication will be described.
\end{abstract}

Several designs are currently being considered for National Ignition Facility capsules. This paper will only describe indirectly driven capsules, i.e., the laser light is converted to x-rays in a gold (typically) hohlraum. The design work separates into two categories: full scale capsules which absorb 150 to $200 \mathrm{~kJ}$ driven by $300 \mathrm{eV}$ x-ray radiation obtained from a $1.3 \mathrm{MJ}$ laser; and reduced scale capsules which absorb about $100 \mathrm{~kJ}$ driven by a $250 \mathrm{eV}$ peak x-ray profile obtained from a $900 \mathrm{~kJ}$ laser. The reduced scale effort checks the viability of capsule designs if, for example, drive symmetry issues forced an enlargement of the hohlraum, thus reducing the attainable peak x-ray drive temperature. Full scale designs (300eV, 1.3MJ laser) consist of ablators made of $\mathrm{CH}$ doped with $\mathrm{Br}$, Be doped with $\mathrm{Cu}$ (distributed in either a uniform or graded fashion), polyimid $\left(\mathrm{C}_{22} \mathrm{H}_{10} \mathrm{~N}_{2} \mathrm{O}_{4}\right)$, and $\mathrm{B}_{4} \mathrm{C}$. To date, design work on reduced scale capsules $(250 \mathrm{eV}, 900 \mathrm{~kJ}$ laser) has concentrated on capsules with only one ablator material: Be with graded $\mathrm{Cu}$ dopant.

All of the capsule designs considered here utilize four shocks to achieve implosion. These shocks are generated by tailoring the laser pulses hitting the hohlraum to produce an x-ray profile having four distinct steps. A convenient way to visualize these shocks is to plot the logarithmic derivitive of the density at each time point in the simulated implosion (Fig. 1). To produce efficient implosions, each of the shocks should break into the fuel in sequence, producing a distinct velocity jump at the gas-ice interface. Mistiming of these shocks be even a slight amount can result in producing very little or no thermonuclear energy.

In addition to shock timing, achieving high implosion velocity is extremely important to successful capsule performance. A convenient way to measure this is to consider the imploding kinetic energy of the DT fuel. Another way to measure this (especially when considering designs with varying amounts of DT fuel) is to construct a "figure of merit" based on the fact that the 
imploding kinetic energy of the fuel must be greater than (or equal to) the energy necessary to ignite the fuel. This figure of merit we define here is simply the ratio of the main fuel kinetic energy to the the energy necessary for ignition. The "energy necessary for ignition" can be crudely estimated by reference to work by Lindl(1) and Levedahl(2) who state:

$$
E_{i g n}=\frac{1}{2}(0.05) \beta^{\frac{3}{2}}\left(\frac{v}{3}\right)^{-5}
$$

where $\mathrm{v}$ is the implosion velocity of the DT fuel and $\beta$ is the ratio of the pressure in the fuel to the Fermi pressure. Unlike final capsule performance indicators like yield, this figure of merit is insensitive to capsule tune and small drive details. Also, it is unambiguous and easy to calculate. We typically quote its peak value to characterize an implosion.

Four capsule designs were selected for study at $300 \mathrm{eV}$ drive. These are shown in Fig. 2. By adjusting the drive for each of the different ablator materials, the DT fuel can be made to implode in a similar fashion. Table 1 lists these capsule designs and several performance characterists: the absorbed energy in kJ, the "figure of merit" defined above, the fuel $\rho r$ in $\mathrm{g} / \mathrm{cm}^{2}$, and the yield in MJ. The Be with uniformly doped $\mathrm{Cu}$ (designed by Wilson, LANL) is included in the table. Absorbed energies range from $150 \mathrm{~kJ}$ for $\mathrm{CH}+\mathrm{Br}$ to $207 \mathrm{~kJ}$ for $\mathrm{Be}+$ uniform $\mathrm{Cu}$. The "figure of merit" which is an indication of implosion velocity, is high for the $\mathrm{CH}+\mathrm{Br}$ and low for the $\mathrm{Be}+$ uniform $\mathrm{Cu}$. Both fuel $\mathrm{\rho r}$ and yield are similar for all designs. Doping of the ablator material serves two main purposes: 1) it provides x-ray preheat shielding of the DT fuel, allowing the fuel to ultimately achieve maximum pressure and density; 2) it alters the density profile at the ablation front; some combinations will then produce less perturbation growth.

Estimating hydrodynamic stability of perturbations during capsule implosion is crucial to evaluating performance of these different designs. This study only investigates perturbations initially on the outer surface of the ablating shell. Other studies have considered the fuel gas-ice surface and the fuel-ablator surface. A perturbation mode spectrum which derives from a smooth Nova plastic capsule can be approximated by the formula (3)

$$
R_{l m}=\varepsilon\left(\frac{6.5 n m}{1+\left(\frac{l \varepsilon}{18}\right)^{5}}+\frac{5.5 n m}{(l \varepsilon+15)^{1.2}}\right)
$$

where $R_{l m}$ is the spherical harmonic amplitude, 1 is the mode number, and $\varepsilon=260 \mu \mathrm{m} /$ (radius).

Combining modes $12,24,36, \ldots 156$ with random phases gives a multimode perturbation amplitude as shown in Fig. 3 with an rms amplitude of $0.031 \mu \mathrm{m}$. Two-dimensional implosion simulation of five potential NIF capsules using this initial multimode perturbation on the outer ablator surface shows significant stability differences. Figure 4 shows the configuration of the 
perturbation at the fuel-ablator interface at the time of maximum interface velocity. That is, the perturbation at this time is the seed for Rayleigh-Taylor perturbation growth as the interface undergoes deceleration from this time forward. The perturbation is significantly larger for the plastic-based capsules than for the Be-based or the $\mathrm{B}_{4} \mathrm{C}$ capsules. The $\mathrm{CH}+\mathrm{Br}$ capsule has $17.1 \mu \mathrm{m}$ perturbation rms, the largest of all, the polyimid has $13.4 \mu \mathrm{m} \mathrm{rms}$; the $\mathrm{B}_{4} \mathrm{C}$ has $7.6 \mu \mathrm{m}$ rms; the $\mathrm{Be}+$ graded $\mathrm{Cu}$ has $6.0 \mu \mathrm{m}$ rms and the $\mathrm{Be}+$ uniform $\mathrm{Cu}$ has $3.7 \mu \mathrm{m}$ rms

An explanation of this difference follows. Figure 5 plots density profiles (scaled) and perturbation rms $(\mathrm{cm})$ for the polyimid capsule and the Be+uniformly doped $\mathrm{Cu}$ capsule at a time just after the second shock has passed through the fuel-shell interface. The position of the third shock is located at the step in the profile and is identified by the "3". The vertical arrows indicate the position of peak density for the two capsules. For capsule radii greater than the position of peak density, a Rayleigh-Taylor unstable condition exists, since low density material (ablated) is pushing a high density material (remaining shell). For capsule radii smaller than the location of peak density, a Rayleigh-Taylor stable condition exists, since high density material is pushing lower density material. The density profile of the plastic ablator allows the RT unstable condition to be in closer proximity to the fuel-shell interface.

Figure 6 shows the one capsule designed (so far) to implode and ignite successfully at a peak drive temperature of $250 \mathrm{eV}$. This Be with graded $\mathrm{Cu}$ dopant capsule absorbs $115 \mathrm{~kJ}$, has a low "figure of merit" (1.08) and a low fuel $\rho r\left(1.28 \mathrm{~g} / \mathrm{cm}^{2}\right)$. One dimensional simulations predict that it produces $5.6 \mathrm{MJ}$ energy. This $250 \mathrm{eV}$ drive is obtained from a $900 \mathrm{~kJ}$ laser. Interestingly, a uniformly doped capsule performs almost as well as this graded dopant design. No stability analysis has been done on this capsule to date.

In summary, several designs appear viable for indirectly driven NIF ignition capsule implosions at $300 \mathrm{eV}$. Each of the ablator materials has specific advantages: $\mathrm{CH}$ (Nova experience); polyimid (material strength); $\mathrm{Be}+\mathrm{Cu}$ (implosion stability); B4C (no doping required). Significant work needs to be done to specify required initial surface finishes for each of these materials. A capsule using a Be ablator with graded $\mathrm{Cu}$ doping has been designed to work at $250 \mathrm{eV}$ x-ray drive from a $900 \mathrm{~kJ}$ laser. Stability analysis and integrated modeling needs to be done on this scaled down capsule.

This work was performed under the auspices of the U. S. Department of Energy by the Lawrence Livermore national Laboratory under contract W-7405-ENG-48.

1) Lindl, J. D. "Development of the indirect drive approach to ICF and the target physics basis for ignition and gain", Physics of Plasmas, Vol. 2, No. 11, Nov. 1995, p3941.

2) Levedahl, W. K. and Lindl, J. D., "Energy scaling of ICF targets for ignition and high gain", (to be published).

3) S. W. Haan, "Initial surface perturbation for NIF hydro instability modeling, (internal memo), Aug. 1994. 


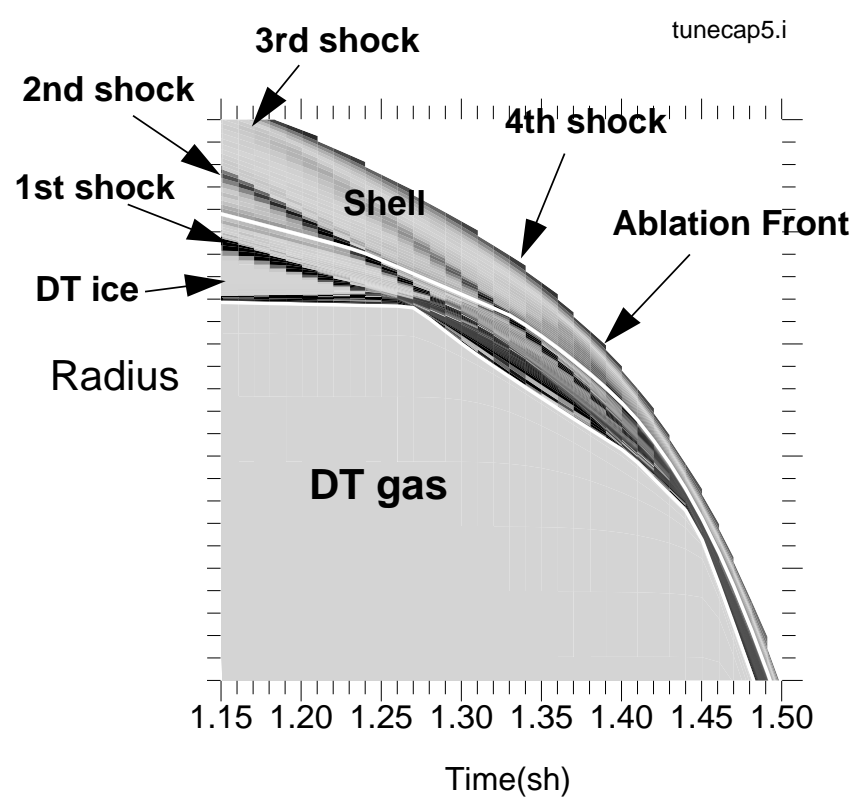

Figure 1. Logarithmic derivative of density versus time for the implosion of a typical NIF capsule

$\operatorname{vg} 960521 . i$

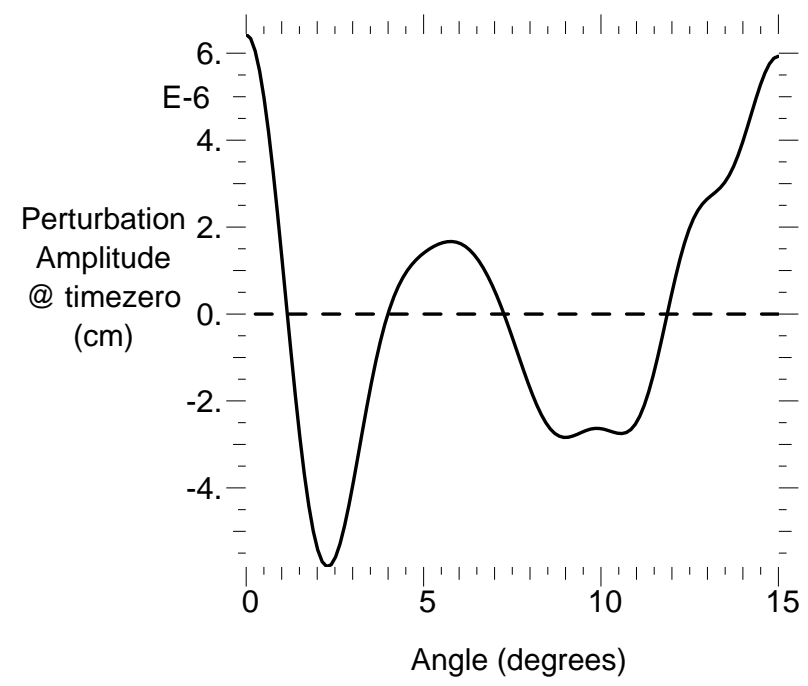

Figure 3. Initial multimode perturbation amplitude versus angle applied to the outer surface of each of the implosion simulations. Cosine modes $12,24,36, \ldots 156$ were combined with random phases to produce this perturbation which has rms of $0.031 \mu \mathrm{m}$, typical for a smooth surfaced Nova capsule.

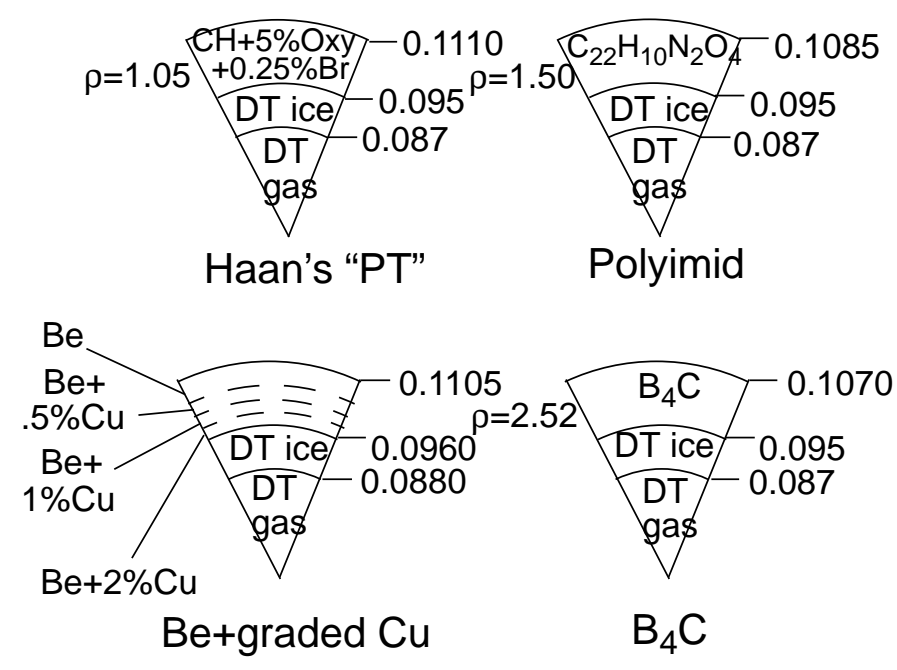

Figure 2. Capsule designs at $300 \mathrm{eV}$ peak drive temperature. vg961003.i

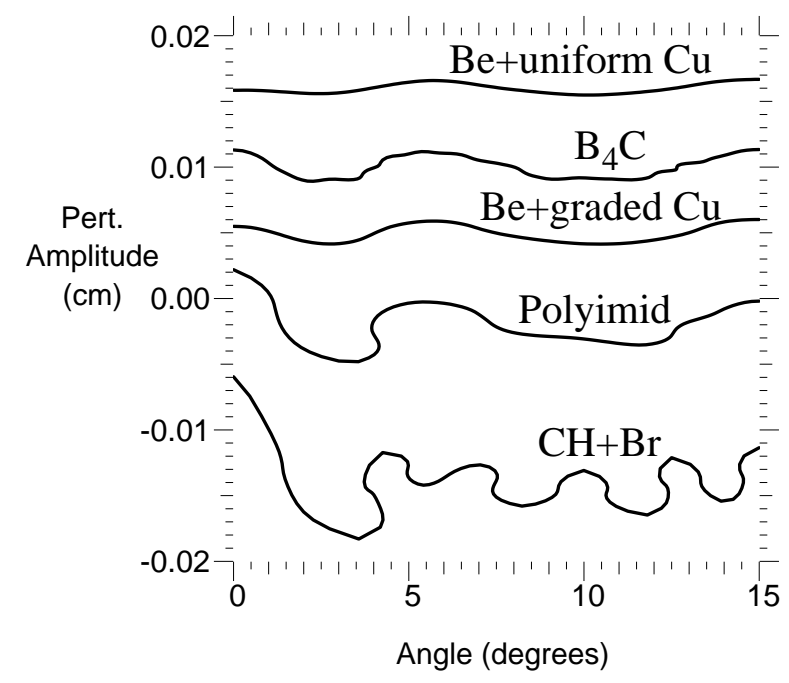

Figure 4. Perturbation amplitude at fuel-shell interface versus angle at time of maximum interface velocity. $\mathrm{CH}+.25 \% \mathrm{Br}$ : rms $=17.1 \mu \mathrm{m}$, polyimid: $r m s=13.4 \mu \mathrm{m}, \mathrm{Be}+$ graded $\mathrm{Cu}: \mathrm{rms}=6.0 \mu \mathrm{m}$, $\mathrm{B}_{4} \mathrm{C}: \mathrm{rms}=7.6 \mu \mathrm{m}, \mathrm{Be}+$ uniform $\mathrm{Cu}: \mathrm{rms}=3.7 \mu \mathrm{m}$. All perturbations are plotted with same vertical scale but offset for ease of viewing. 


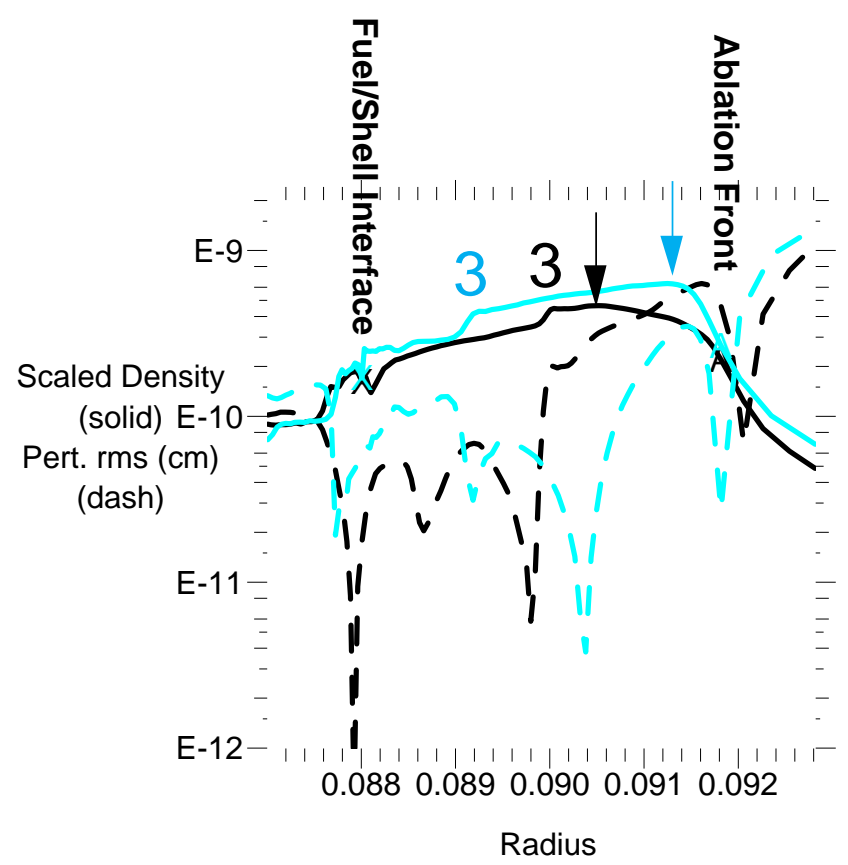

Figure 5. Density (scaled) (solid) and perturbation rms (dashed) versus radius for polyimid ablator capsule (black) and $\mathrm{Be}+$ uniform $\mathrm{Cu}$ ablator capsule (gray). Position of fuel-shell interface and the ablation front are indicated. The numbers " 3 " indicate position of the third shock as it proceeds inward. The arrows indicate the position of peak density in each of the density profiles.

Table 1: NIF Capsule Performance

\begin{tabular}{|l|l|l|l|l|}
\hline \multicolumn{1}{|c|}{ Capsule } & $\begin{array}{c}\text { Absorbed } \\
\text { Energy } \\
(\mathrm{kJ})\end{array}$ & $\begin{array}{c}\text { Figure } \\
\text { of } \\
\text { Merit }\end{array}$ & $\begin{array}{c}\rho_{\text {fuel }} \\
\left(\mathrm{g} / \mathrm{cm}^{2}\right)\end{array}$ & $\begin{array}{c}\text { Yield } \\
(\mathrm{MJ})\end{array}$ \\
\hline \hline $\mathrm{CH}+.25 \% \mathrm{Br}$ & 150 & 4.5 & 1.67 & 13.5 \\
\hline Polyimid & 158 & 2.6 & 1.63 & 17.5 \\
\hline Be+graded $\mathrm{Cu}$ & 171 & 3.5 & 1.60 & 15.9 \\
\hline $\mathrm{B} 4 \mathrm{C}$ & 199 & 3.5 & 1.75 & 18.0 \\
\hline $\begin{array}{l}\text { Be+.9\% } \mathrm{Cu} \\
(\text { Wilson })\end{array}$ & 207 & 1.5 & 1.54 & 19.6 \\
\hline
\end{tabular}

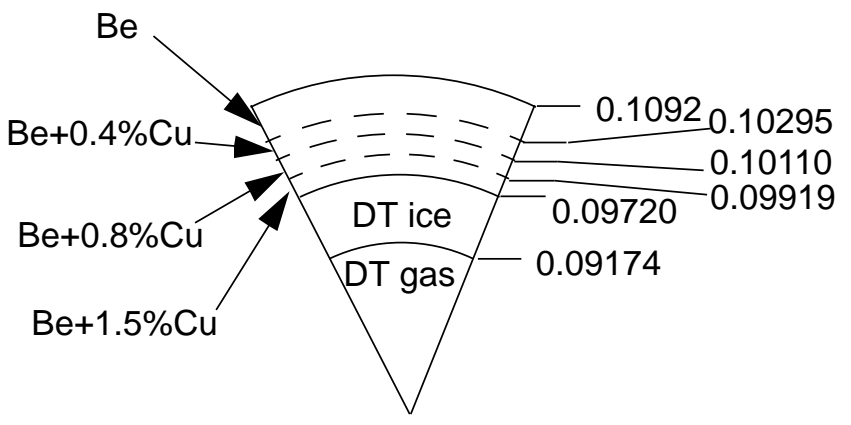

Figure 6. This NIF capsule using a Be ablator doped with graded $\mathrm{Cu}$ and driven by a $250 \mathrm{eV}$ peak $\mathrm{X}$-ray drive profile from a $900 \mathrm{~kJ}$ laser can produce 5.6 MJ fusion energy. 


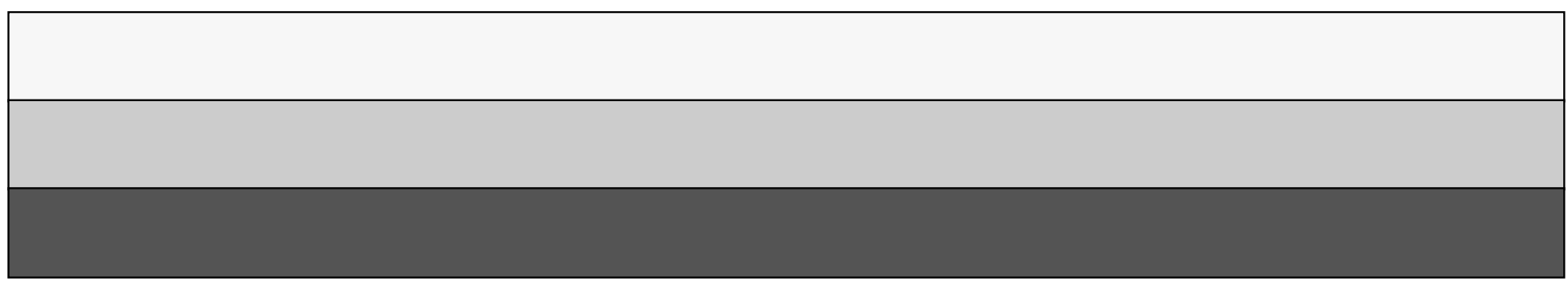

